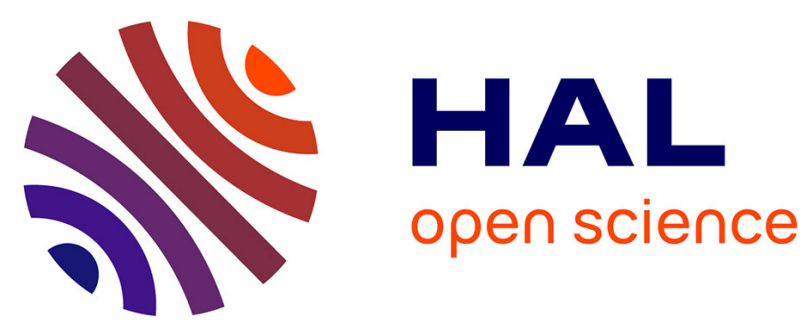

\title{
Enzyme-based biohybrid foams designed for continuous flow heterogeneous catalysis and biodiesel production
}

Nicolas Brun, Annick Babeau-Garcia, Marie-France Achard, Clément Sanchez, Fabien Durand, Guillaume Laurent, Marc Birot, Hervé Deleuze, Rénal Backov

\section{- To cite this version:}

Nicolas Brun, Annick Babeau-Garcia, Marie-France Achard, Clément Sanchez, Fabien Durand, et al. Enzyme-based biohybrid foams designed for continuous flow heterogeneous catalysis and biodiesel production. Energy Environmental Science, 2011, 4, pp. 2840-2844. 10.1039/c1ee01295a . hal00620449

\section{HAL Id: hal-00620449 \\ https://hal.science/hal-00620449}

Submitted on 24 Jan 2020

HAL is a multi-disciplinary open access archive for the deposit and dissemination of scientific research documents, whether they are published or not. The documents may come from teaching and research institutions in France or abroad, or from public or private research centers.
L'archive ouverte pluridisciplinaire HAL, est destinée au dépôt et à la diffusion de documents scientifiques de niveau recherche, publiés ou non, émanant des établissements d'enseignement et de recherche français ou étrangers, des laboratoires publics ou privés. 


\title{
Enzyme-based biohybrid foams designed for continuous flow heterogeneous catalysis and biodiesel production $\dagger$
}

\author{
Nicolas Brun, ${ }^{a}$ Annick Babeau-Garcia, ${ }^{a}$ Marie-France Achard,,${ }^{a}$ Clément Sanchez,${ }^{c}$ Fabien Durand,${ }^{a}$ \\ Guillaume Laurent, ${ }^{c}$ Marc Birot, ${ }^{b}$ Hervé Deleuze ${ }^{* b}$ and Rénal Backov ${ }^{* a}$
}

Received 14th March 2011, Accepted 17th May 2011

DOI: 10.1039/c1ee01295a

The one-pot synthesis and use of monolithic biohybrid foams in a continuous flow device reported in here presents the advantages of covalent stabilization of the enzymes, together with a low steric hindrance between proteins and substrates, optimized mass transport due to the interconnected macroporous network and simplicity with regard to the column in situ synthetic path. Those features, when applied to transesterification (biodiesel production) via enzyme catalysis, provide among the top enzymatic activities displayed by biohybrid catalysts bearing unprecedented endurance of continuous catalysis for a two month period.

Modern societies will be confronted in the near future with an increasing requirement of fuels combined with a programmed diminution of easily extractable resources of fossil origin. In this context,

${ }^{a}$ Centre de Recherche Paul Pascal, UPR 8641-CNRS, Université de Bordeaux, 115 Avenue Albert Schweitzer, 33600 Pessac, France. E-mail: backov@crpp-bordeaux.cnrs.fr

${ }^{b}$ Université de Bordeaux, Institut des Sciences Moléculaires (ISM) UMR5255-CNRS, 351 Cours de la Libération, 33405 Talence, France. E-mail: $h$. deleuze@ism.u-bordeaux1.f

${ }^{c}$ Laboratoire Chimie de la Matière Condensée de Paris (LCMCP) UMR7574 UPMC-CNRS, Collège de France, 11, place Marcelin Berthelot, 75231, Paris Cedex 05, France

$\uparrow$ Electronic supplementary information (ESI) available. See DOI: $10.1039 / \mathrm{clee} 01295 \mathrm{a}$ biodiesels, which are fatty acid methyl or ethyl esters obtained by transesterification of vegetable oils, have attracted considerable attention during the last decade. ${ }^{1}$ Several processes for biodiesel fuel production have been developed, among which transesterification with alcohol using mineral acids, ${ }^{2}$ or base $^{3}$ catalysts is the most common. Alkali-catalyzed alcoholysis, which is about 4000 times faster than its acid-catalyzed counterpart, is commonly used in industrial processes. ${ }^{3}$ Despite the fact that this process is inexpensive and highly efficient, it is not yet completely satisfactory. Particularly, the presence of both water and free fatty acids in the reaction medium causes a partial saponification, leading to a loss of catalytic efficiency. ${ }^{1}$ Recently, enzymatic transesterification using lipases (triacylglycerol hydrolases), has become an interesting alternative for biodiesel fuel production, since the problems mentioned above can be circumvented. ${ }^{4}$ The main hurdle to the industrialization of this system is the cost of lipases, which is significantly higher than that of the alkali. Consequently, it is necessary to develop processes insuring a complete recyclability and stability of enzymatic catalysts over the time, in order to reduce the impact of this cost increase down to competitive levels. Immobilization or entrapment of biocatalysts, ${ }^{5}$ onto or within porous materials using either physical adsorption, ${ }^{6}$ covalent attachment, ${ }^{7}$ inclusion or encapsulation by a sol-gel route, ${ }^{8}$ represents an attractive and efficient approach to facilitate their use in continuous devices, and to compete with cheaper processes. ${ }^{9-12}$ Therefore, the design of new functional porous materials to immobilize active biomacromolecules still presents a challenge of both

\section{Broader context}

Modern societies will be confronted in the near future with an increasing requirement of fuels combined with a programmed diminution of easily extractable resources of fossil origin. In this context, biodiesels, which are fatty acid methyl or ethyl esters obtained by transesterification of vegetable oils, have attracted considerable attention during the last decade. Particularly, enzymatic transesterification using lipases has become an interesting alternative for biodiesel fuel production. We present the synthesis and use of an enzyme-based macrocellular green catalyst in continuous flow devices where reactant mass transport has been reached. Overall, the one-pot synthesis and use of monolithic biohybrid foams in a continuous flow device reported here presents the advantages of covalent stabilization of the enzymes, together with a low steric hindrance between proteins and substrates, an optimized mass transport due to the interconnected macroporous network and simplicity with regard to the column in situ synthetic path. Those features, when applied to transesterification (biodiesel production) via enzyme catalysis, provide among the top enzymatic activity displayed by biohybrid catalysts bearing unprecedented endurance of continuous catalysis for a two month period. 
economic and ecological interests. In this context, functional ordered macro-mesoporous materials prepared according to the concept of "integrative chemistry" ${ }^{13}$ are of interest for multiple applications in heterogeneous catalysis, separation techniques, purification of wastewaters, sensors, optics etc. ${ }^{14}$ Within this aim, our research group has developed a way to obtain hybrid macrocellular silica-based monoliths, labelled "Organo-Si(HIPE)" ("HIPE" for High Internal Phase Emulsion), ${ }^{15}$ exhibiting a hierarchically structured porosity. Using the same strategy, combined with the concept of immobilized biocatalysts, we have designed a new series of biohybrid foams labelled Lipase@Organo-Si(HIPE), exhibiting high catalytic performances. ${ }^{16}$ Herein, we present the synthesis and use of enzyme-based macrocellular materials in continuous flow devices in order to optimize reactant mass transport. Continuous flow monolithic microreactors, ${ }^{17}$ offer the possibility to circumvent some drawbacks associated with the use of batch reactors; such as limited productivity (low TON), complex control of heat transfer, high maintenance costs, security concerns, etc. In the present work, silica-based biohybrid monolithic foams have been synthesized in situ in a PTFE-coated stainless steel chromatography column by combining the sol-gel process with the concentrated emulsion soft templating approach (Fig. 1a). In order to covalently anchor the enzymes onto the inner monolith walls, epoxy groups have been grafted using a continuous flow impregnation with (3-glycidyloxypropyl)trimethoxysilane as organosilane precursor. Then, commercial crude lipases have been immobilized by continuous flow impregnation in distilled water (at $\mathrm{pH}=6.5$ ). Epoxy groups are very attractive candidates to generate short and soft covalent spacer arms and to react with different nucleophiles present on the surface of enzyme molecules, for instance amino, thiol, or hydroxyl groups. ${ }^{18,19}$ This feature allows us to reach a good compromise between stability of the grafting and mobility of the protein, allowing, as observed in several cases, an increase of the immobilized enzyme activity. ${ }^{20}$ Finally, after exhaustive continuous flow washings, the column containing the monolith, called $\mathrm{Col}[\mathrm{C}$ CR-lipase]@gGlymo-Si(HIPE), was placed in the oven, and connected to a pump to be used in continuous flow catalysis (see ESI for the column characterization details over the micro-meso and macroscopic length scales). As can be seen in Fig. 1b-c, after 60 days of catalytic use, the Col[C-CR-lipase]@gGlymo-Si(HIPE) monolith presents a low shrinkage (around 8\%) demonstrating the absence of a significant preferential flow circulation between the inner surface of the column and the outer surface of the monolith during use (Fig. 1d). Moreover, considering the low flow rate used in this study $(0.1 \mathrm{~mL}$ $\mathrm{min}^{-1}$ ), together with the bottom-up flow direction restricting gravity effects, and the relatively high viscosity of the moving fluid, creeping motion (Stokes flow) can be considered. This situation, characteristic of microfluidic systems, is favourable for a good contact between the reagents onto the flow and the catalyst (the enzyme) situated near the walls. The first reaction studied using this device was the esterification of oleic acid by 1-butanol in a diluted heptane solution (Fig. 2). For an initial reagents solution flow rate of $0.05 \mathrm{~mL} \mathrm{~min}^{-1}$, the daily conversion level in butyl oleate is relatively stable around 50\% during twenty days (Fig. 2a). However, when increasing this flow rate level to

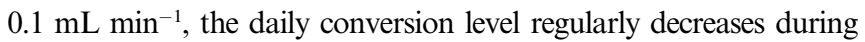
the thirty following days down to about $15 \%$. The conversion level increased when returning to the initial flow rate. This behaviour can be attributed to a consistent dehydration of the enzyme on the silicabased support, water acting as a molecular lubricant. ${ }^{21}$ As a direct consequence, the quite high initial enzymatic activity (Fig. 2b),

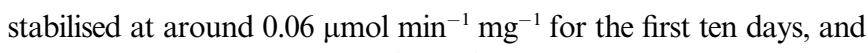
decreased to $0.03 \mu \mathrm{mol} \mathrm{min} \mathrm{mg}^{-1}$ for the last five days of the continuous flow reaction (the column stoichiometry and enzymatic loading can be found within the ESI). Moreover, enzyme deactiva-tion through modification of its conformation by alcohol cannot be excluded. Nevertheless, after 50 days of continuous flow catalysis at 37 ${ }^{\circ} \mathrm{C}$, the enzymatic activity retains about $50 \%$ of its initial value. This result is, to the best of our knowledge, unprecedented for continuous flow enzymatic catalysis. ${ }^{11,22,23}$ At that stage, the low concentration of substrates in heptane solution used in this experi-ment remains an important drawback for future applications. Therefore, another continuous flow catalysis experiment has been performed using a more concentrated starting reagents solution (50 wt $\%$ in heptane). In this experiment, a crude vegetable oil, safflower oil from Carthamus tinctorius seed, has been chosen for trans-esterification with ethanol (Fig. 3). This oil is principally composed of two unsaturated triglycerides: trilinolein (around 70\%) and triolein (around 10\%), and completed with tripalmitin $(8 \%) .{ }^{24}$ For this reac-tion we have previously demonstrated that the Candida rugosa lipase is not the candidate of choice, being less active than the Thermomyces

Lanuginosus lipase. ${ }^{16}$ Therefore, a new column has been synthesized using the same approach as previously and called $\mathrm{Col}$ [C-TL-lipase] @ g glymo-Si(HIPE) (see ESI for this column characterization details over the micro-meso and macroscopic length scales). The evolution of the conversion in butyl linoleate versus time is reported in Fig. 3. For a reagents solution flow rate of $0.05 \mathrm{~mL} \mathrm{~min}^{-1}$, the daily conversion level in butyl linoleate is initially close to $40 \%$, and decreases slowly but regularly to reach finally about $15 \%$ after two months of continuous conversion. As pointed out for the esterification reaction, this behaviour can be attributed to both a consistent dehydration of the enzyme ${ }^{21}$ and a degradation of the enzyme conformation through the ethanol source. It is now possible to compare the performance of the Col[C-TL-lipase]@gGlymo-Si(HIPE) column with other supported-enzyme catalysis under continuous flux reported in the literature. Particularly, it is reported that the use of lipase Candida $s p$. confined within textile fibers is associated either with a $20 \%$ decrease of enzymatic activity within 21 days of catalysis under continuous flux ${ }^{25}$ or with a $16 \%$ decrease within 4 days of continuous catalytic reaction. ${ }^{10}$ We also have to mention that a good enzymatic stability over 5 days (conversion of $80 \%$ under continuous flow) has been obtained for stabilized lipase Candida antarctica B(Novozyme 435), confined within macroporous acrylic resin in the transesterification of worn palm oil. ${ }^{26}$ Using the same enzyme, Royon et al. have reported a conversion of $95 \%$ during 21 days when considering the transesterification of coconut oilseed with methanol. ${ }^{27}$ Under this study it 
has been established that tert-butanol, bearing a weak polarity, favors dissolution of glycerol by-products. In that case, $1.7 \mathrm{mg}$ of enzyme per gram of oil has been used, allowing a methyl linoleate production of $0.17 \mu \mathrm{mol} \mathrm{min}{ }^{-1} \mathrm{mg}^{-1}$ (enzyme) during 21 days. In our case the methyl

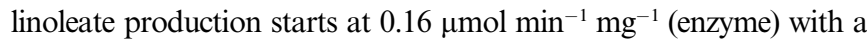

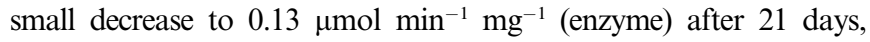
production that is decreasing but still effective after two months of

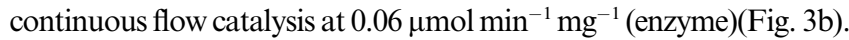

Overall, the one-pot synthesis and use of monolithic biohybrid foams in a continuous flow device reported in this work presents the advantages of covalent stabilization of the enzymes, together with a low steric hindrance between proteins and substrates, an optimized mass transport due to the interconnected macroporous network and simplicity in regard of the column in situ synthetic path. Those features, applied to the enzyme-catalyzed transesterification reaction (biodiesel production), exhibit amongst the top enzymatic activity addressed with biohybrid catalysts displaying unprecedented endurance of continuous catalysis for a two month period.

\section{Experimental section}

\section{Materials}

Tetraethylorthosilane (TEOS), tetradecyltrimethylammonium bromide (TTAB), (3-glycidyloxypropyl)trimethoxysilane and dodecane were purchased from Fluka (St. Louis, MO). Lipase from Candida Rugosa (E.C.3.1.1.3, Type VII, $700 \mathrm{U} \mathrm{mg}^{-1}$ ), lipase from
Thermomyces Lanuginosus (solution, $\geq 100000 \mathrm{U} \mathrm{g}^{-1}$ ), carthame oil (purified safflower oil), oleic acid, glyceryl trilinoleate (98\%), ethyl linoleate $(\geq 99 \%)$, linoleic acid $(\geq 99 \%)$, n-heptane, ethanol and 1-butanol were purchased from Sigma Chemical (St. Louis, MO). Other chemicals and solvents used in this study were of analytical grade or HPLC grade.

\section{Hybrid monolithic column synthesis}

Typically, $5 \mathrm{~g}$ of TEOS was added to $16 \mathrm{~g}$ of a TTAB aqueous solution at $35 \mathrm{wt} \%$ previously acidified $(7 \mathrm{~g}$ of $\mathrm{HCl})$, and hydrolysis occurred until a monophasic hydrophilic medium was obtained. The oily phase constituted $35 \mathrm{~g}$ of dodecane which was then emulsified drop by drop into the hydrophilic continuous phase using a mortar. The emulsion was then allowed to condense for 1 week at room temperature in a PTFE pipe $(L=251.0 \mathrm{~mm} ; r=9.65 \mathrm{~mm})$ confined in a stainless steel HPLC-type column lined with a PTFE tube $(7 \mathrm{~mm}$ ID diameter, $300 \mathrm{~mm}$ useful length). The as-synthesized monolith was washed for four days in a tetrahydrofuran-acetone mixture (at $50 \mathrm{vol} \%)$ under continuous flow $\left(0.1 \mathrm{~mL} \mathrm{~min}^{-1}\right)$ to extract the oily (dodecane) phase from the monolith. Then, epoxy groups were grafted by a closed-loop continuous flow impregnation $\left(0.1 \mathrm{~mL} \mathrm{~min}^{-1}\right)$ of a $0.05 \mathrm{M}$ solution of (3-glycidyloxypropyl)trimethoxysilane (Glymo) in chloroform $(200 \mathrm{~mL})$ for three days. The hybrid silica-based column was then successively washed with chloroform, acetone and water $\left(0.5 \mathrm{~mL} \mathrm{~min}^{-1}\right)$.

\section{Esterification catalysis reactions using Candida rugosa crude lipase-based monolithic column}

Crude lipase from Candida rugosa (500 mg; Sigma Chemical; E. C.3.1.1.3, Type VII, $700 \mathrm{U} \mathrm{mg}^{-1}$ ) was dispersed into distilled water $(200 \mathrm{~mL})$. The mixture was first stirred for an hour at room temperature and centrifuged for $5 \mathrm{~min}$ at $5000 \mathrm{rpm}$ to eliminate the insoluble compounds. Then, the hybrid column was impregnated by this solution in a closed-loop continuous flow process (flow rate: $0.1 \mathrm{~mL} \mathrm{~min}^{-1}$ ) for five days at room temperature. The as-synthesized biohybrid column is then left for one month at $4{ }^{\circ} \mathrm{C}$ in the static enzymatic aqueous solution. After that, the column was continuously washed with distilled water, until disappearance of absorbance by Bradford measurement, ${ }^{28}$ and then with heptane (flow rate:

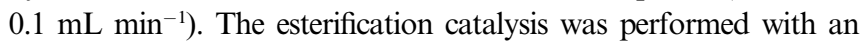
oleic acid $\left(23 \mathrm{mmol} \mathrm{L}^{-1}\right)$ and 1-butanol $\left(46 \mathrm{mmol} \mathrm{L}^{-1}\right)$ heptane solution under a $0.1 \mathrm{~mL} \mathrm{~min}{ }^{-1}$ flow rate at $37^{\circ} \mathrm{C}$. Formation of the ester was monitored using HPLC, to determine the conversion yield.

\section{Transesterification catalysis reactions using Thermomyces lanuginosus crude lipase-based monolithic column}

Crude lipase from Thermomyces lanuginosus ( $4 \mathrm{~g} ; \geq 100000 \mathrm{U} \mathrm{g}^{-1}$ ) was dispersed into distilled water $(200 \mathrm{~mL})$. The mixture was first stirred for an hour at room temperature. The hybrid column was impregnated by this solution in a closed-loop continuous flow process (flow rate: $0.1 \mathrm{~mL} \mathrm{~min}^{-1}$ ) during five days at room temperature. The as-synthesized biohybrid column was left for two weeks at $4{ }^{\circ} \mathrm{C}$ in the static enzymatic aqueous solution. After, the column was continuously washed with distilled water until disappearance of absorbance by Bradford measurement. ${ }^{28}$ In a second step, the biohybrid column was activated with a $5 \% \mathrm{w} / \mathrm{v}$ glutaraldehyde aqueous solution (200 mL) 0in a closed-loop continuous flow process (flow rate: 
$0.1 \mathrm{~mL} \mathrm{~min}^{-1}$ ) during three days at room temperature. The activated biohybrid column was then functionalized with a new enzymatic aqueous solution ( $4 \mathrm{~g}$ TL crude lipase in $200 \mathrm{~mL}$ distilled water) by continuous flow impregnation (flow rate: $0.1 \mathrm{~mL} \mathrm{~min}^{-1}$ ) during five days at room temperature. The column was then continuously washed with distilled water, until disappearance of absorbance by Bradford measurement, and with heptane (flow rate: $0.1 \mathrm{~mL} \mathrm{~min}{ }^{-1}$ ). The transesterification of crude safflower oil from Carthamus tinctorius seed $(38 \mathrm{wt} \%)$ by ethanol $(12 \mathrm{wt} \%)$ was performed in heptane

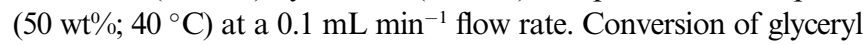
trilinoleate was monitored using HPLC.

\section{Characterizations}

Scanning electron microscopy (SEM) observations were performed with a Hitachi TM-1000 apparatus operating at $15 \mathrm{kV}$. The specimens were sputtered with $\mathrm{Au} / \mathrm{Pd}$ prior to examination.

\section{HPLC analytical system}

The analytical system consisted of a 600 solvent delivery system, manual injector (Waters, Milford, MA, USA). The compounds were separated on an Atlantis $\mathrm{DC}_{18}(4.6 \mathrm{~mm} \times 150 \mathrm{~mm}, 5 \mu \mathrm{m})$ column with an Atlantis $\mathrm{DC}_{18}$ guard column (Waters). The column was operated at room temperature. Empower software (Waters) was used for data acquisition and processing. Standards were dissolved in tertbutyl methyl ether (MTBE). All solutions were filtered through a $0.45 \mu \mathrm{m}$ membrane and degassed before use. The flow-rate was

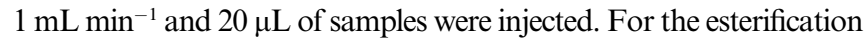
catalyzed reactions a refractometer 410 (Waters, Milford, MA, USA) was used for detection. The mobile phase was acetonitrile (grade HPLC), isocratic elution. For the transesterification catalyzed reactions the detector in use was an ultraviolet diode array 996 (Waters, Milford, MA, USA). The maximum absorbance was at $\lambda=204 \mathrm{~nm}$. A gradient elution was used. Solvent A: acetonitrile, solvent B: tertbutyl methyl ether. A: $4 \mathrm{~min} 100(\mathrm{v} / \mathrm{v})$ isocratic, A-B: $2 \mathrm{~min} \mathrm{70-30}$ (v/v) gradient, A-B: $10 \min 70-30$ (v/v), A: $0.5 \mathrm{~min} 100$ (v/v) gradient. Then, the column was equilibrated under conditions mentioned above for $10 \mathrm{~min}$.

\section{References}

1 H. Fukuda, A. Kondo and H. Noda, J. Biosci. Bioeng., 2001, 92, 405.

2 M. I. Al-Widyan and A. O. Al-Shyoukh, Bioresour. Technol., 2002, 85, 253.

3 M. J. Nye, T. W. Williamson, S. Deshpande, J. H. Shrader, W. H. Snively, T. P. Yurkewich and C. R. French, J. Am. Oil Chem. Soc., 1983, 60, 1598.

4 M. S. Antczak, A. Kubiak, T. Antczak and S. Bielecki, Renewable Energy, 2009, 34, 1185.

5 A. M. Klibanov, Science, 1983, 219, 722.

6 G. Zhou, Y. Chen and S. Yan, Microporous Mesoporous Mater, 2009, 119, 223.

7 G. Mateo, G. Fernandez-Lorente, O. Abian, R. Fernandez-Lafuente and J. M. Guisan, Biomacromolecules, 2000, 1, 739.

8 M. T. Reetz, A. Zonta and J. Simplekamp, Biotechnol. Bioeng., 1996, 49, 527.

9 B. V. Kabasakal and A. Caglar, Energy Fuels, 2010, 24, 1269.

10 Y. Chen, B. Xiao, J. Chang, Y. Fu, P. Lv and X. Wang, Energy Convers. Manage., 2009, 50, 668.

11 P. Lozano, E. Garcia-Verdugo, R. Piamtongkam, N. Karbass, T. De Diego, M. I. Burguete, S. V. Luis and J. L. Iborra, Adv. Synth. Catal., 2007, 349, 1077.

12 E. Calleri, C. Temporini, S. Furlanetto, F. Loiodice, G. Fracchiolla and G. Massolini, J. Pharm. Biomed. Anal., 2003, 32, 715.
13 (a) R. Backov, Soft Matter, 2006, 2, 452; (b) E. Prouzet, S. Ravaine, C. Sanchez and R. Backov, New J. Chem., 2008, 32, 1284.

14 (a) N. Brun, S. Ungureanu, H. Deleuze and R. Backov, Chem. Soc. Rev., 2011, 40, 771; (b) C. Sanchez, P. Belleville, M. Popall and L. Nicole, Chem. Soc. Rev., 2011, 40, 696.

15 (a) N. Brun, B. Julian-Lopez, P. Hesemann, G. Laurent, H. Deleuze, C. Sanchez, M.-F. Achard and R. Backov, Chem. Mater., 2008, 20, 7117; (b) S. Ungureanu, M. Birot, H. Deleuze, O. Babot, M.-F. Achard, M. I. Popa, C. Sanchez and R. Backov, Appl. Catal., $A$, 2010, 390, 51; (c) S. Ungureanu, H. Deleuze, M. I. Popa, C. Sanchez and R. Backov, Chem. Mater., 2008, 20, 6494; (d) S. Ungureanu, M. Birot, L. Guillaumme, H. Deleuze, O. Babot, B. Julian-Lopez, M.-F. Achard, M. I. Popa, C. Sanchez and R. Backov, Chem. Mater., 2007, 19, 5786; (e) S. Ungureanu, M. Birot, L. Guillaumme, H. Deleuze, O. Babot, M.-F. Achard, M. I. Popa, C. Sanchez and R. Backov, Colloids Surf., A, 2010, 360, 85.

16 N. Brun, A. Babeau-Garcia, H. Deleuze, F. Duran, C. Sanchez, V. Ostreicher and R. Backov, Chem. Mater., 2010, 22, 4555.

17 (a) A. El Khadib, R. Chimenton, A. Sachse, F. Fajula, A. Galarneau and B. Coq, Angew. Chem., Int. Ed., 2009, 48, 4969; (b) N. Brun, H. Deleuze, C. Sanchez and R. Backov, French Patent, FRI056099, 2010; (c) A. Sachse, A. Galarneau, B. Coq and F. Fajula, New J. Chem., 2011, 35, 259.

18 C. Mateo, V. Grazù, J. M. Palomo, F. Lopez-Gallego, R. FernandezLafuente and J. M. Guisan, Nat. Protoc., 2007, 2, 1022.

19 C. Mateo, G. Fernandez-Lorente, O. Abian, R. Fernandez-Lafuente and J. M. Guisan, Biomacromolecules, 2000, 1, 739.

20 C. Mateo, O. Abian, R. Fernandez-Lafuente and J. M. Guisan, Enzyme Microb. Technol., 2000, 26, 509.

21 J. A. Rupley and G. Careri, Adv. Protein Chem., 1991, 41, 37.

22 N. A. Serri, A. H. Kamaruddin and K. Y. Tau Len, Food Bioprod. Process., 2010, 88, 327.

23 A. Marty, D. Combes and J.-S. Condoret, Biotechnol. Bioeng., 1994, 43, 497.

24 B. Bozan and F. Temelli, Bioresour. Technol., 2008, 99, 6354.

25 K. Nie, F. Xie, F. Wang and T. Tan, J. Mol. Catal. B: Enzym., 2006, 43, 142.

26 S. F. A. Halim, A. H. Kamaruddin and W. J. N. Fernando, Bioresour. Technol., 2009, 100, 710.

27 D. Royon, M. daz, G. Ellenrieder and S. Locatelli, Bioresour. Technol., 2007, 98, 648.

28 M. M. Bradford, Anal. Biochem., 1976, 72, 248. 

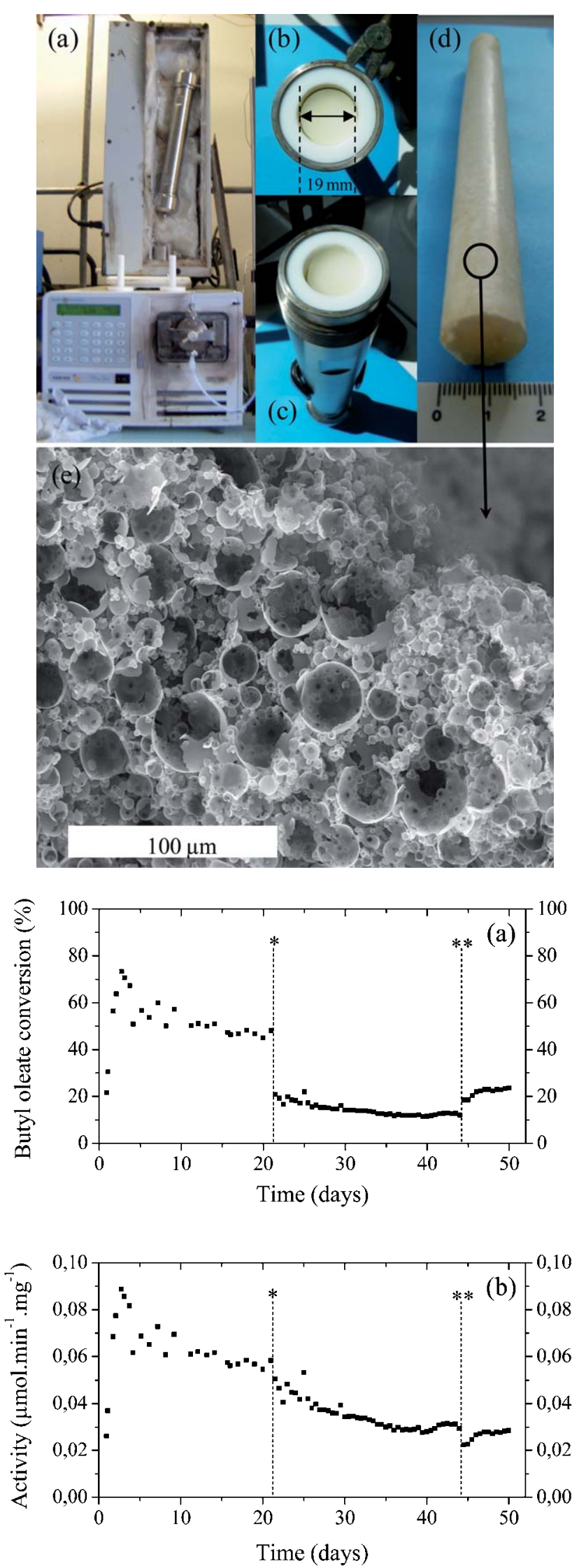

Fig. 2 Catalytic performances for esterification of oleic acid with 1butanol in heptane obtained using Col[C-CR-lipase]@gGlymo-Si(HIPE). Initial flow rate is $0.05 \mathrm{~mL} \mathrm{~min}^{-1}$. ${ }^{*}$ The flow rate is increased to $0.1 \mathrm{~mL}$ $\mathrm{min}^{-1}$, ** the flow rate positioned back to $0.05 \mathrm{~mL} \mathrm{~min}^{-1}$. (a) Butyl oleate conversion versus time; (b) enzymatic activity versus time. The enzymatic activity is expressed in $\mu \mathrm{mol}$ of butyl oleate consumed per minute and per milligram of lipase immobilized. Examples of HPLC chromatograms are shown within the ESI.
Fig. 1 Pictures of: (a) the continuous flow set-up; (b, c) the as-synthe-sized column after 60 days of continuous flow transesterification catalysis within the stainless steel canister; (d) the biohybrid macrocellular column extracted from its canister after 60 days of continuous flow esterification catalysis. The two set of columns used in this study are labelled Col[C$C R$-lipase]@gGlymo-Si(HIPE) and Col[C-TL-lipase]@gGlymo-Si (HIPE).
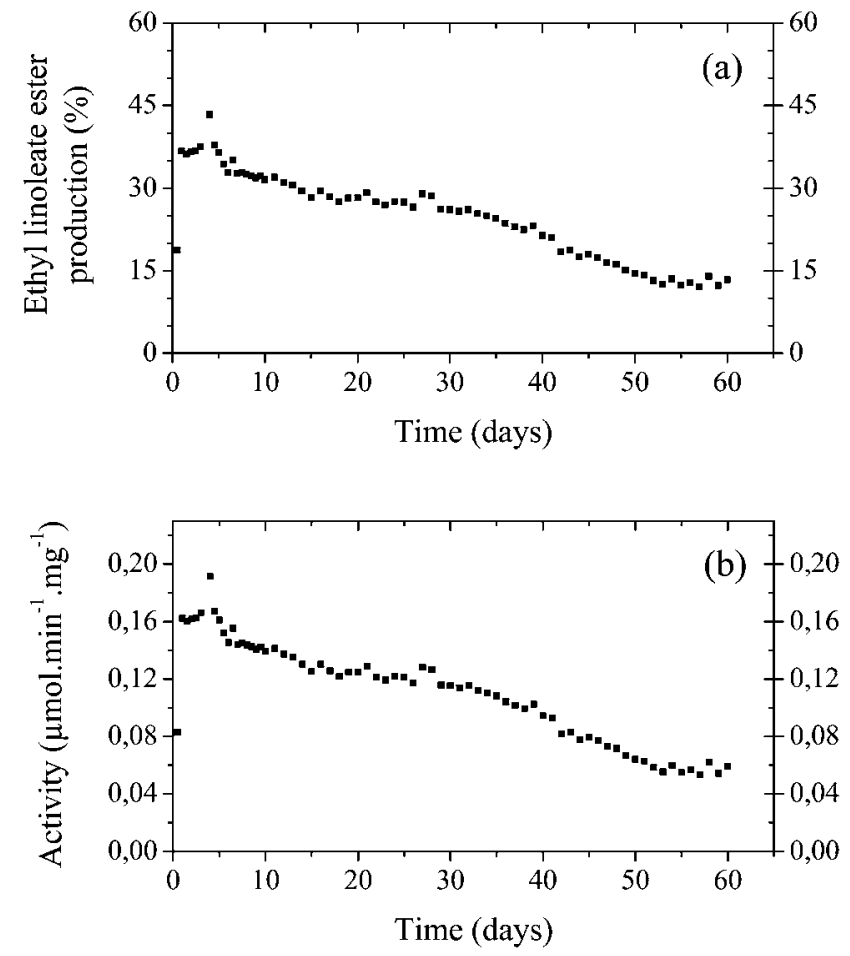

Fig. 3 Catalytic performances for transesterification of safflower oil with ethanol in heptane obtained using Col[C-TL-lipase]@gGlymo-Si (HIPE) at $40{ }^{\circ} \mathrm{C}$ at a $0.1 \mathrm{~mL} \mathrm{~min}^{-1}$ flow rate. (a) Ethyl linoleate ester production versus time; (b) enzymatic activity versus time. The enzymatic activity is expressed in $\mu \mathrm{mol}$ of ethyl linoleate ester produced per minute and per milligram of lipase immobilized. Examples of HPLC chro-matograms are shown within the ESI. 


\section{Supplemental}

\section{Characterizations details.}

Scanning Electron Microscopy (SEM) observations were performed with a Hitachi TM-1000 apparatus at $15 \mathrm{kV}$. The specimens were sputtered with $\mathrm{Au} / \mathrm{Pd}$ prior to examination. Intrusion/ extrusion mercury measurements were performed using a Micromeritics Autopore IV apparatus in order to assess the scaffolds' macrocellular cells characteristics. Small Angle Xray Scattering (SAXS) experiments were carried on a $18 \mathrm{~kW}$ rotating anode X-ray source (Rigaku-200) with use of Ge (111) crystal as monochromator. The scattered radiation was collected on a two dimensional detector (Imaging Plate system from Mar Research, Hamburg). The sample- detector distance was $500 \mathrm{~mm}$. Surface areas and pore characteristics at the micro- and mesoscale were obtained through nitrogen adsorption-desorption experiments using a Micromeritics ASAP 2010. ${ }^{29}$ Si Nuclear Magnetic Resonance (NMR) spectra were recorded on a Bruker Avance III 300 spectrometer (7 T) operating at 59.6 MHz. Samples were spun at $5 \mathrm{kHz}$ using $7 \mathrm{~mm}$ Zquotors. The ${ }^{29}$ Si MAS NMR spectra were performed with a $90^{\circ}$ pulse of $5 \mu$ s and a recycle delay of $150 \mathrm{~s}$. The spectra were deconvoluted with the DMFIT program [1].

\section{Supplementary results.}

Biohybrid monolithic columns have been thoroughly characterized after use in continuous flow catalysis. For doing so, silica-based foams has been washed with distilled water and freeze-dried 24 hours, in order to keep as much as possible the structure of the hybrid framework. These macroporous materials have been examined by Scanning Electron Microscopy (SEM, Figure S1). Micrographs clearly reveal for both monolithic columns, the typical interconnected macroporous network of $\mathrm{Si}(\mathrm{HIPE}) \mathrm{s}$ materials, constituted of an aggregated hollow spheres-like macrostructure (hollow spheres are usually named voids or cells) [2]. This feature is mainly due to a privileged mineralization at the oil/water interface of 
the soft template concentrated emulsion. Moreover, a high interconnectivity between void spaces is highlighted by internal junctions (see green solid arrow on Figure S1b), connecting two directly adjacent cells, and external junctions (see red dotted arrow on Figure S1b), induced by statistical aggregation of oil droplets during emulsification process.
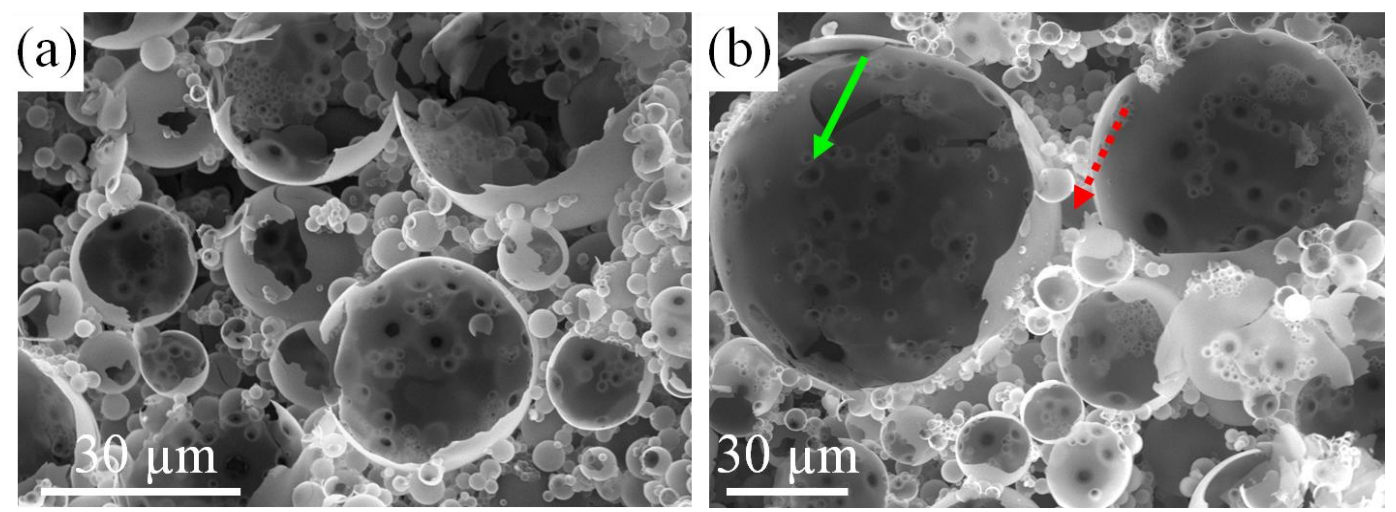

Figure S1. Scanning electron micrographs (SEM) of the biohybrid macroporous columns after continuous flow catalysis, washing and freeze-drying. (a) Col[C-CR-lipase]@gGlymo-Si(HIPE) and (b) Col[C-TLlipase]@gGlymo-Si(HIPE). The green solid arrow indicates an internal cell junction, whereas the red dotted arrow corresponds to an external cell junction.

High interconnectivity between voids is also emphasized by mercury intrusion porosimetry data (Figure S2). At this stage, it is necessary to remind that mercury porosimetry provides only informations about the junctions, also named windows, that connect adjacent void spaces, and not on the cellular void spaces themselves. Pores size distribution for both monolithic columns exhibit a main windows diameter centered on $10 \mu \mathrm{m}$, probably related to external junctions, together with a less-defined shoulder, between $100 \mathrm{~nm}$ and $2 \mu \mathrm{m}$, feature that can be associated with narrow internal junctions (see arrows on Figure S2). 

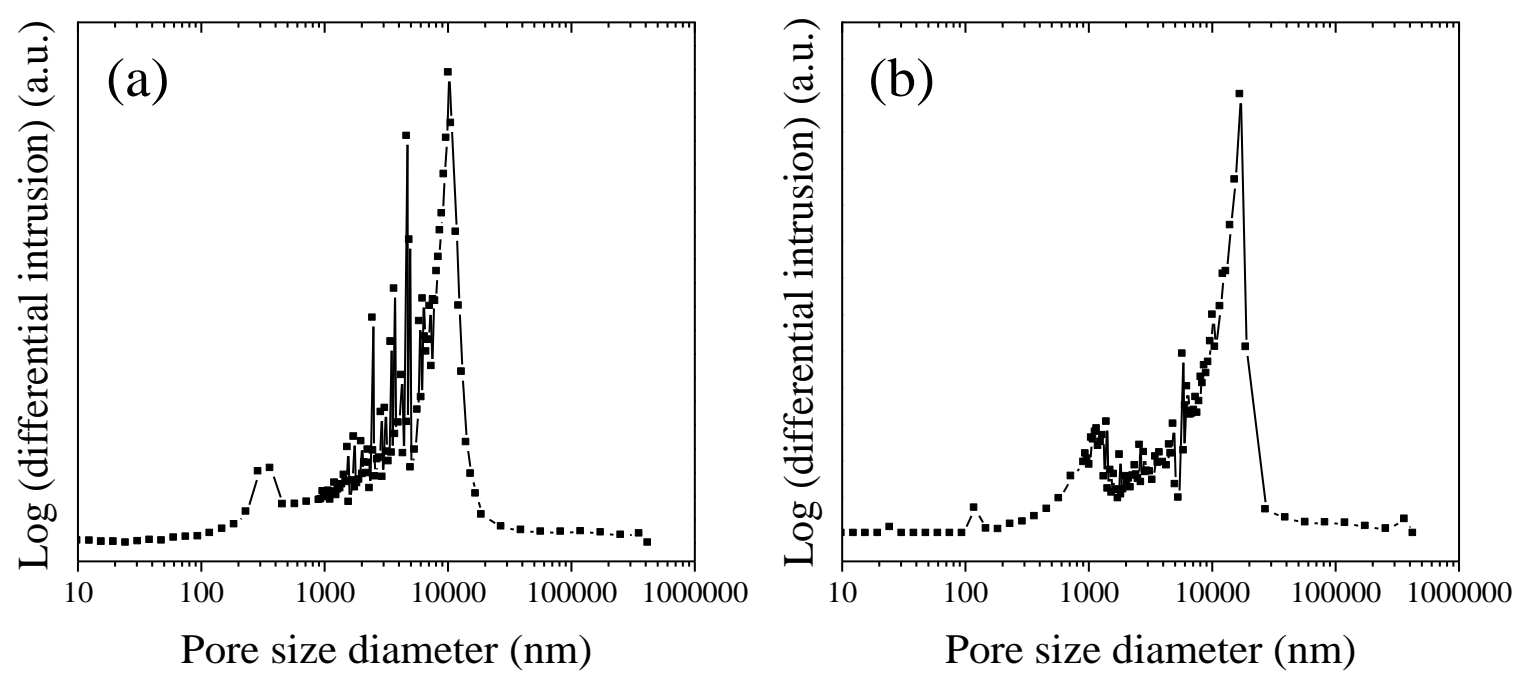

Figure S2. Pore size distributions of the biohybrid macroporous columns after continuous flow catalysis, washing and freeze-drying, determined by mercury intrusion porosimetry. (a) Col[C-CR-lipase]@gGlymoSi(HIPE) and (b) Col[C-TL-lipase]@gGlymo-Si(HIPE).

In conjunction with a high interconnectivity between void spaces, these biohybrid monolithic columns exhibit elevated macroporosities, close to $95 \%$, and intrusion volumes, up to $20.1 \mathrm{~cm}^{-3} \cdot \mathrm{g}^{-1}$, as revealed by mercury porosimetry data (Table S1). A higher skeletal density can be noticed for the Col[C-TL-lipase]@gGlymo-Si(HIPE). This feature will be discussed later.

Table S1. Mercury intrusion porosimetry data of the biohybrid macroporous columns after continuous flow catalysis, washing and freeze-drying.

\begin{tabular}{cccc}
\hline Biohybrid foams & Porosity $(\%)$ & $\begin{array}{c}\text { Intrusion volume } \\
\left(\mathrm{cm}^{-3} \cdot \mathrm{g}^{-1}\right)\end{array}$ & $\begin{array}{c}\text { Skeletal density } \\
\left(\mathrm{g} \cdot \mathrm{cm}^{-3}\right)\end{array}$ \\
\hline $\begin{array}{c}\text { Col[C-CR-lipase] } \\
@ g \text { Glymo-Si(HIPE) }\end{array}$ & 95 & 20.0 & 1.0 \\
$\begin{array}{c}\text { Col[C-TL-lipase }] \\
@ g \text { Glymo-Si(HIPE) }\end{array}$ & 94 & 13.0 & 1.2 \\
\hline
\end{tabular}

Beyond macroporosity, these foams exhibit some degree of mesoporosity, induced by supramolecular self-assembly of the cationic surfactants used to stabilize oil-water interfaces of the native concentrated emulsion. Indeed, small-angle X-ray scattering profiles (SAXS, 
Figure S3) of these materials constantly depict a broad peak centered at a wave vector, q, of $0.144 \AA^{-1}$. This feature clearly discloses a vermicular mesostructure, associated with an unit cell parameter around $4.4 \mathrm{~nm}$, in agreement with previous results obtained for $\mathrm{Si}$ (HIPE)s without thermal treatment [2].

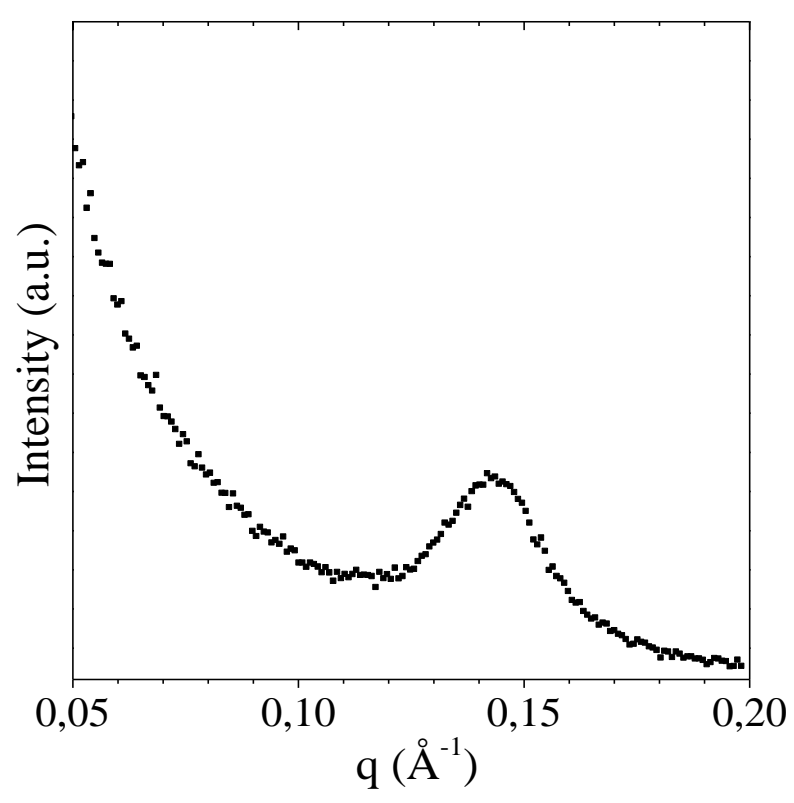

Figure S3. Small-angle X-ray scattering profile of a biohybrid macroporous column after continuous flow catalysis, washing and freeze-drying.

The presence of mesopores is also confirmed by nitrogen sorption experiments (Figure S4). Concerning the Col[C-CR-lipase]@gGlymo-Si(HIPE) sample, a mixed type II/ type IV isotherm can be noticed, exhibiting a hysteresis of the desorption curve compared with the adsorption one (Figure S4a). This hysteresis clearly highlights a capillary condensation phenomenon, induced by the presence of mesopores within the hybrid silica-based framework. Moreover, a fast rise of the nitrogen adsorption at the very low relative pressures (up to 0,04 ) involves a microporous component, while the progressive increase of the $\mathrm{N}_{2}$ amount adsorbed above relative pressure of 0.2 and up to 1.0, strongly suggests a multimolecular adsorption, relative to macropores (Figure S4a). On the other hand, the nitrogen sorption curve noticed for the Col[C-TL-lipase]@gGlymo-Si(HIPE) sample depicts a 
type II isotherm, strongly suggestive of an essentially macroporous material (Figure S4c). The lack of a fast $\mathrm{N}_{2}$ sorption rise at the very low relative pressures implies an absence or a minor accessibility of micropores. The pore size distributions, obtained by density functional theory for both hybrid foams (Figure S4b-d), show constantly a broad peak centered at 3-4 $\mathrm{nm}$, in agreement with SAXS data (Figure S4). Nevertheless, a less marked hysteresis is discernible for the Col[C-TL-lipase]@gGlymo-Si(HIPE), suggesting a reduced accessibility to the mesoporous component.
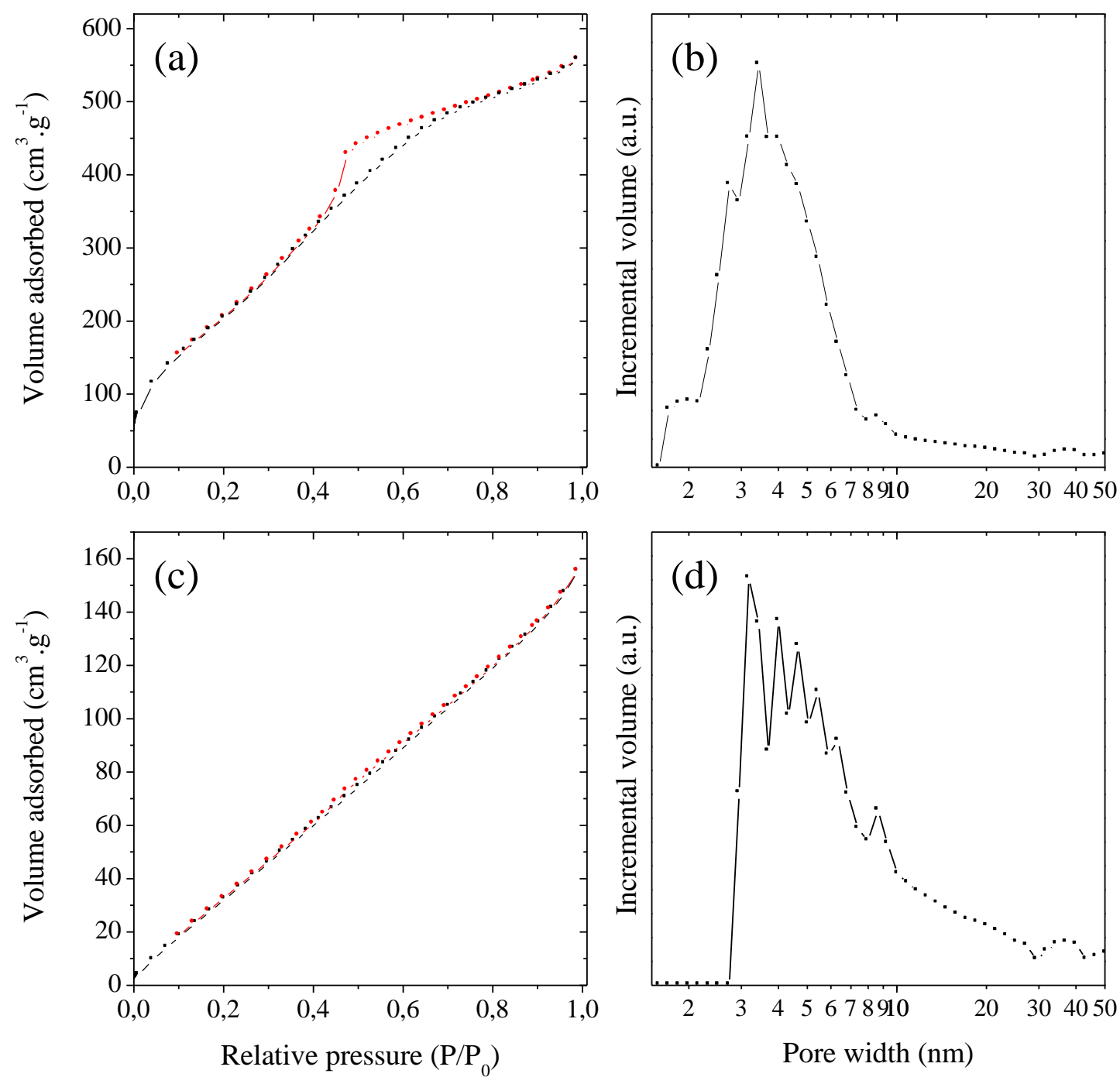

Figure S4. Nitrogen sorption isotherms for (a) Col[C-CR-lipase]@gGlymo-Si(HIPE) and (c) Col[C-TLlipase]@gGlymo-Si(HIPE). Pore size distributions obtained by Density Functional Theory (DFT) for (b) Col[C$C R$-lipase]@gGlymo-Si(HIPE) and (d)Col[C-TL-lipase]@gGlymo-Si(HIPE). 
Theses features can be explained by a larger amount of biomolecules within the Col[C-TL-lipase]@gGlymo-Si(HIPE) hybrid framework, inducing a partial obstruction of nitrogen molecules towards the smaller pores (typically, micro- and mesopores). This characteristic, confirmed by both Brunauer, Emmett, Teller (BET) and Barret, Joyner, Halenda (BJH) data (Table S2), will be discussed by comparing stoichiometries and enzymatic loadings of each column.

Table S2. Nitrogen sorption data for the biohybrid macroporous columns after continuous flow catalysis, washing and freeze-drying.

\begin{tabular}{ccccc}
\hline Biohybrid foams & $\begin{array}{c}\text { BET surface area } \\
\left(\mathrm{m}^{2} \cdot \mathrm{g}^{-1}\right)^{\mathrm{a}}\end{array}$ & $\begin{array}{c}\text { Mesoporous } \\
\text { surface area } \\
\left(\mathrm{m}^{2} \cdot \mathrm{g}^{-1}\right)^{\mathrm{b}}\end{array}$ & $\begin{array}{c}\text { Total porous } \\
\text { volume } \\
\left(\mathrm{cm}^{3} \cdot \mathrm{g}^{-1}\right)^{\mathrm{c}}\end{array}$ & $\begin{array}{c}\text { Mesoporous } \\
\text { volume } \\
\left(\mathrm{cm}^{3} \cdot \mathrm{g}^{-1}\right)^{\mathrm{b}}\end{array}$ \\
\hline $\begin{array}{c}\text { Col[C-CR-lipase] } \\
\text { @ gGlymo-Si(HIPE) }\end{array}$ & 962 & 541 & 0.86 & 0.61 \\
$\begin{array}{c}\text { Col[C-TL-lipase] } \\
\text { @ gGlymo-Si(HIPE) }\end{array}$ & 210 & 143 & 0.24 & 0.21 \\
\hline calculated using the BET model, ${ }^{\mathrm{b}}$ calculated using the BJH model, ${ }^{\mathrm{c}}$ calculated using the single point model
\end{tabular}

To quantify the degree of grafting and condensation of organosilane derivatives (epoxy groups) anchored within the silica-based frameworks, a study by ${ }^{29} \mathrm{Si}$ nuclear magnetic resonance (NMR) at the magic angle spinning (MAS), was conducted (Figure S5 and Table S3). ${ }^{29} \mathrm{Si}$ sites are labeled with the conventional $\mathrm{T}_{\mathrm{n}}$ and $\mathrm{Q}_{\mathrm{n}}$ notations. $\mathrm{T}$ refers to functional $(\mathrm{R}) \mathrm{SiO}_{\mathrm{n}}(\mathrm{OH})_{3-\mathrm{n}}$ units, induced by organosilane precursors grafting, and $\mathrm{Q}$ to $\mathrm{SiO}_{\mathrm{n}}(\mathrm{OH})_{4-\mathrm{n}}$ units, associated with native silica-based scaffold (n being the number of bridging oxygen atoms, generated by the condensation process, surrounding the silicon). Chemical shifts were determined relative to TMS (tetramethylsilane). Due to the presence of both the $T_{n}$ and $Q_{n}$ signals, the efficient grafting of the organosilane derivative is confirmed for both monolithic porous microreactors (Figure S5). 

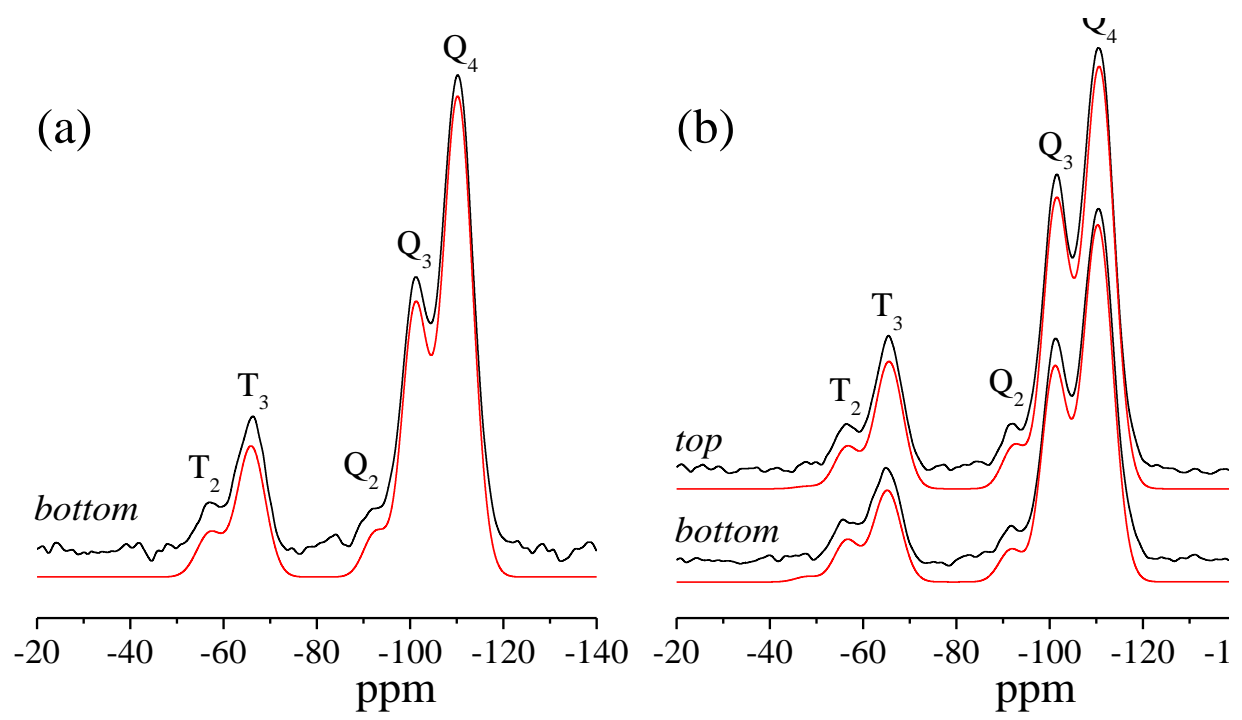

Figure S5. ${ }^{29} \mathrm{Si}$ nuclear magnetic resonance spectra obtained at the magic angle spinning for (a) Coll[C-CRlipase]@gGlymo-Si(HIPE) and (b) Col[C-TL-lipase]@gGlymo-Si(HIPE). NMR MAS experiments have been performed at the lower part (bottom), together with the upper part (top) of the Col[C-TL-lipase]@gGlymo$\mathrm{Si}(\mathrm{HIPE})$ column.

After a Lorentzian/Gaussian deconvolution of the NMR spectra, atomic compositions in $T_{n}$ and $Q_{n}$ species can be determined (Table $\left.S 3\right)$. Thus, concerning both grafting $\left(T_{n} /\right.$ $\left.\left(T_{n}+Q_{n}\right)\right)$ and condensation $\left(T_{3} / T_{2}\right)$ degrees, no difference can be noticed between the two hybrid columns, revealing a good reproducibility of the continuous flow functionalization process. Moreover, no grafting gradient can be observed between the lower and the upper parts of the as-synthesized biohybrid Col[C-TL-lipase]@gGlymo-Si(HIPE), suggesting an homogeneous functionalization within the porous scaffold. 
Table S3. Molar percentages of $Q_{n}$ and $T_{n}$ units and molar ratio $T_{3} / T_{2}$ (condensation degree) calculated from the integration of NMR peaks after a Lorentzian/Gaussian deconvolution. NMR MAS experiments have been performed at the lower part (bottom), together with the upper part (up) of the Col[C-TL-lipase]@gGlymo$\mathrm{Si}(\mathrm{HIPE})$ column.

\begin{tabular}{rcccc}
\hline \multirow{2}{*}{ Biohybrid foams } & & \multicolumn{3}{c}{$R M N M A S^{29} \mathrm{Si}$} \\
\cline { 3 - 5 } & & $\% \mathrm{Q}_{\mathrm{n}}$ & $\% \mathrm{~T}_{\mathrm{n}}$ & $\mathrm{T}_{3} / \mathrm{T}_{2}$ \\
\hline $\begin{array}{c}\text { Col[C-CR-lipase] } \\
\text { @ } g \text { Glymo-Si(HIPE) }\end{array}$ & bottom & 82.2 & 17.8 & 3.2 \\
Col[C-TL-lipase] & bottom & 82.0 & 18.0 & 2.5 \\
$@ g$ Glymo-Si(HIPE) & up & 80.5 & 19.5 & 3.2 \\
\hline
\end{tabular}

Beyond organosilane precursors grafting, the enzymatic loadings were determined by the Bradford [3] assay using bovine serum albumin as a standard, checking the protein content of both impregnation and washing solutions. At this stage, it can be noticed that a larger amount of lipases has been immobilized within the Col[C-TL-lipase]@gGlymo-Si(HIPE) foam. This feature is mainly explained by the two-step procedure, involving an intermediate activation of the biohybrid macroporous monolith with a $5 \%$ w./v. glutaraldehyde aqueous solution. Indeed, the formation of Cross-Linked Enzyme Aggregates (CLEAs) [4], covalently bonded via glutaraldehyde's bridges, can be strongly suggested. The overall biohybrid column stoichiometries can be found within table S4.

Table S4. Lipase loadings and stoichiometries of the biohybrid columns determined by both ${ }^{29} \mathrm{Si}$ nuclear magnetic resonance and Bradford assay.

\begin{tabular}{ccc}
\hline \multicolumn{2}{c}{ Immobilized lipases } & Stœchiometries ${ }^{\mathrm{c}}$ \\
\cline { 1 - 2 } Weight $(\mathrm{mg})$ & \\
\hline Candida rugosa & $9.4^{\mathrm{a}}(57 \%)^{\mathrm{b}}$ & Col $[\mathrm{C}-C R \text {-lipase }]_{5.4 .10^{-6}} @ \mathrm{SiO}_{1.82}\left(\mathrm{C}_{6} \mathrm{O}_{2} \mathrm{H}_{11}\right)_{0.18}$ \\
Thermomyces lanuginosus & $158^{\mathrm{a}}(81 \%)^{\mathrm{b}}$ & Col $[\mathrm{C}-T L \text {-lipase }]_{1.7 .10^{-4}} @ \mathrm{SiO}_{1.82}\left(\mathrm{C}_{6} \mathrm{O}_{2} \mathrm{H}_{11}\right)_{0.18}$ \\
\hline
\end{tabular}

${ }^{a}$ Amounts of enzymes immobilized determined by Bradford assay. ${ }^{b}$ Percentages of enzymes immobilized related to the initial lipase weight used in the solution of impregnation.

We can notice that the enzyme loading is around one hundred times higher for the column Col[C-TL-lipase]@gGlymo-Si(HIPE) than the Col[C-CR-lipase]@gGlymo-Si(HIPE). 
This feature hast two consequences. First the higher enzyme loading will avoid nitrogen access to the mesocopic void paces when performing $\mathrm{N}_{2}$ adsorption-desorption measurement. As a direct consequence, the specific surface area should be smaller for the Col[C-CRlipase]@gGlymo-Si(HIPE), as it is the case considering both figure S4 and table $\mathrm{S} 2$. Also, considering the high molecular weight of the protein in use, a loading higher with a factor 100 for the Col[C-TL-lipase]@gGlymo-Si(HIPE), will undoubtedly increase the foams skeletal density as it observed above considering table S1, where mercury porosimetry results are summarized. Considering these hybrid foams, the effects of the embedded [5] or grafted [6] organic content over the final mesoporosity and skeletal density are well known and reported.

\section{Examples of HPLC chromatograms.}
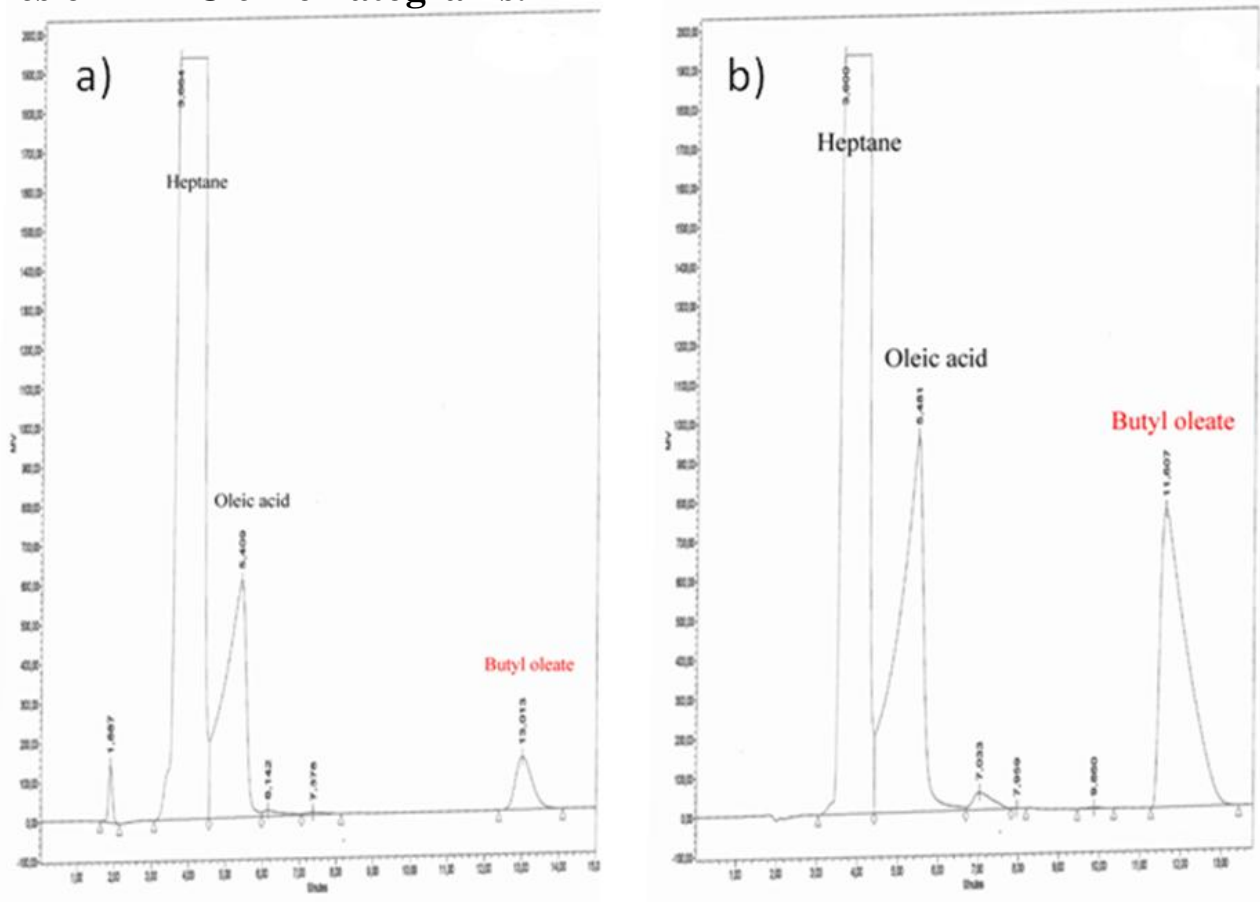

Figure S6. HPLC chromatograms a) after 6 days of esterification, b) after after 40 days of esterification. 

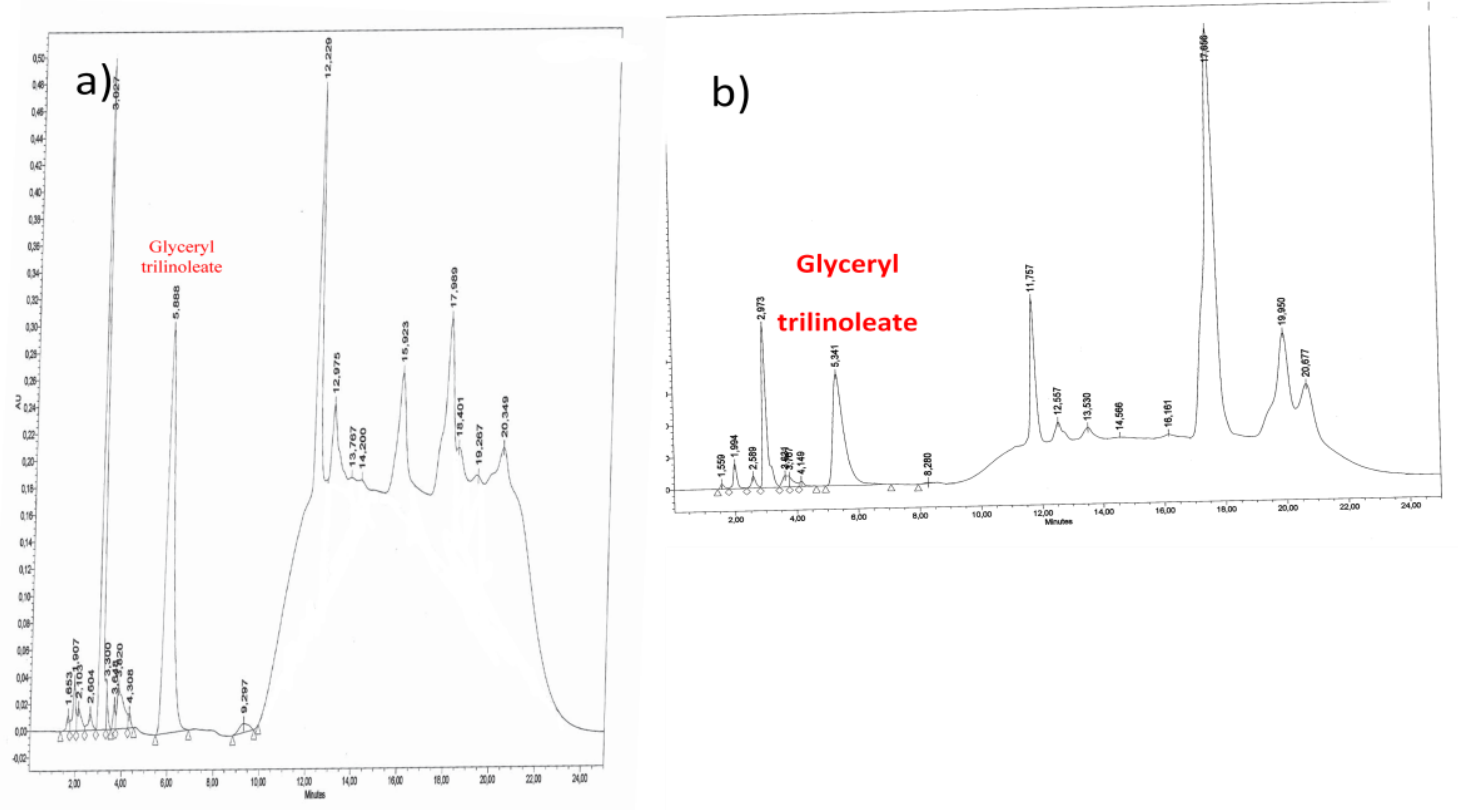

Figure S7. HPLC chromatograms a) after 10 days of transesterification, b) after after 60 days of transesterification.

\section{References}

[1] (a) R.K. Harris, M.L. Robbins, Polymer 1978, 19, 1123. (b) F. Babonneau, New J. Chem. 1994, 18, 1065. (c) Y. Chevalier, A.-C. Grillet, M.-I. Rahmi, C. Lière, M. Masure, P. Hémery, F. Babonneau, Mater. Sci. Engin. C 2002, 21, 143.

[2] F. Carn, A. Colin, M.-F. Achard, M. Birot, H. Deleuze, R. Backov, J. Mat. Chem. 2004, $14,1370$.

[3] M.M. Bradford, Anal Biochem. 1976, 72, 248.

[4] B.C. Kim, S. Nair, J. Kim, J.H. Kwak, J.W. Grate, S.H. Kim, M.B. Gu, Nanotechnology $\mathbf{2 0 0 5}, 16, \mathrm{~S} 382$.

[5] S. Ungureanu, M. Birot, L. Guillaumme, H. Deleuze, O. Babot, B. Julian-Lopez, M.-F. Achard, M. I. Popa, C. Sanchez, R. Backov, Chem. Mater. 2007, 19, 5786.

[6] S. Ungureanu, H. Deleuze, M. I. Popa, C. Sanchez, R. Backov, Chem. Mater. 2008, 20, 6494. 